Available online at GSC Online Press Directory

GSC Biological and Pharmaceutical Sciences

e-ISSN: 2581-3250, CODEN (USA): GBPSC2

Journal homepage: https://www.gsconlinepress.com/journals/gscbps

(RESEARCH ARTICLE)

\title{
Critical appraisal of multiple sclerosis guideline in Indonesia
}

\author{
Pinzon Rizaldy Taslim ${ }^{1, *}$ and Renita Sanyasi Rosa De Lima ${ }^{2}$ \\ ${ }^{1}$ Duta Wacana School of Medicine, Dr. Wahidin Sudiro Husodo Street 5-25, Kotabaru, Gondokusuman, Yogyakarta, \\ 55224. \\ ${ }^{2}$ Dr. Efram Harsana Air Force Hospital, Raya Solo Street, Maospati, Magetan, East Java, 63392, Indonesia.
}

Publication history: Received on 11 September 2018; revised on 08 October 2018; accepted on 13 October 2018

Article DOI: https://doi.org/10.30574/gscbps.2018.5.2.0099

\begin{abstract}
Multiple sclerosis (MS) is an autoimmune disease and an incurable. The MS guideline is available in Indonesia. The guideline was developed by Indonesian Neurological Association. The appraisal of these guideline is not yet performed. The aim of this study is to assess the quality of multiple sclerosis guidelines in Indonesia using Appraisal of Guidelines for Research and Evaluation II (AGREE II) instrument. The search was obtained to identify MS guideline in Indonesia. The guideline assessed using AGREE II instrument. There are 23 key items organized within 6 domains and each key items were rated on a 7-point scale. After calculating each domain, the result interpreted as: (i) a strongly recommended for use in practice, (ii) recommended for use with some modification, or (iii) not recommended for use in practice. There was only one MS guideline in Indonesia, developed by Indonesian Neurological Association called "Perdossi” in 2015. Most of the domain score percentage were more than 50\%. Domain 4 got the highest score percentage (94.44\%), followed by domain 2 (88.89\%), domain 1 (83.33\%), and domain 5 (54.17\%). The guideline had a spesific recommendations and easily identifiable in an algorithms, tables, or summary boxes. The guideline's objectives, target populations, target users, and development group were clearly described. The lowest score percentage was domain 6 (33.33\%) because lack of related informations. Critical appraisal of the Indonesian MS guideline using AGREE II instrument showed a good result. The Indonesian MS guideline was strongly recommended for use in practice.
\end{abstract}

Keywords: Multiple sclerosis; Guidelines; Indonesia; Critical appraisal

\section{Introduction}

Multiple sclerosis (MS) is an autoimmune disease, a chronic, debilitating, neurodegenerative disease that has a high impact on patients' quality of life [1-2]. The worldwide prevalence of MS is estimated more than 2 million, but there are considerable geographic differences, for example MS prevalence is ranging from 110 cases per 100,000 persons in the northern United States to 47 per 100,000 in the southern United States [3-4]. MS attacks people from age 15 to 45 years, with the peak age of onset is 29 years [5].

MS seen as an inflammatory demyelinating disease, characterized by the formation of focal demyelinated plaques in the white matter of the central nervous system [6]. The cause is unknown, but it appears to involve a combination of genetic susceptibility and a nongenetic trigger, such as a virus, metabolism, or environmental factors, that together result in a self-sustaining autoimmune disorder that leads to recurrent immune attacks on the CNS [7]. Typical symptoms of MS include sensory disturbances, motor weakness, optic neuritis, Lhermitte sign, fatigue, and impaired coordination [2]. Diagnostic criteria for multiple sclerosis (MS) include clinical and paraclinical laboratory assessments. McDonald criteria is the most common criteria to diagnose MS [8]. There are some techniques to aid in diagnosis, including: magnetic resonance imaging (MRI), cerebrospinal fluid (CSF) analysis, and the use of evoked potentials (EP) [9].

\footnotetext{
${ }^{*}$ Corresponding author

E-mail address: drpinzon17@gmail.com
}

Copyright (C) 2018 Author(s) retain the copyright of this article. This article is published under the terms of the Creative Commons Attribution Liscense 4.0. 
MS is an incurable disease. Many medications and other measures may be used to ameliorate MS symptoms. These medications help control the underlying disease process, probably by decreasing immune mediated inflammation [10]. Multiple Sclerosis guidelines should be focused not only on basic treatment, but also on the diagnostic of MS, treatment of relapses, and long-term preventive treatment [11]. The MS guideline is available in Indonesia. Indonesian Neurological Association developed the guideline. The appraisal of this guideline is not yet performed. The aim of this study was to assess the quality of multiple sclerosis guidelines in Indonesia using Appraisal of Guidelines for Research and Evaluation II (AGREE II) instrument.

\section{Material and methods}

A systematic search was performed to collect relevant MS guideline in Indonesia. The guideline was obtained by reviewing the homepages of Indonesian neurologist society, medical institution and other relevant websites. The search were conducted using keywords: multiple sclerosis guideline, "tatalaksana multipel sklerosis", and "guideline multipel sklerosis di Indonesia".

The inclusion criteria to select guidelines are: (a) the guideline was from Indonesia, (b) the full text was available, (c) the guideline was written in Indonesian, and (d) the guideline published between 2012 to 2017. Guidelines were excluded if: (i) did not meet the criteria of guideline and (ii) focused on only one type of multiple sclerosis, such as: relapsing-remitting MS.

The selected guideline was evaluated by 2 appraisers, using Appraisal of Guidelines for Research \& Evaluation II (AGREE II) instrument. AGREE II is an international instrument to assess the quality of guidelines. There are 23 key items organized within 6 domains: (1) scope and purposes, (2) stakeholder involvement, (3) rigour of development, (4) clarity of presentation, (5) applicability, and (6) editorial independence. Each key items are rated on a 7-point scale, 1-strongly disagree to 7-strongly agree by two reviewers. The key item scored 1 if there was little or no information that is relevant to AGREE II criteria and scored 7 if the key items fulfill the criteria. Score between 2 and 6 was assigned when the key items did not meet the full criteria. In the end, the scores in each domain calculated into a single quality score using the following formula: (obtained score - minimum possible score / maximum possible score - minimum possible score) $\mathrm{x}$ $100 \%$ [12]. After calculating each domain, the result interpreted as: (i) a strongly recommended for use in practice if most domains scored above 50\%, (ii) recommended for use with some modification if most domains scored between $30 \%$ to $50 \%$, or (iii) not recommended for use in practice if most domains scored below $30 \%$.

\section{Results and discussion}

The searched was conducted based on inclusion and exclusion criteria. There was only one MS guideline in Indonesia [12]. The title of the guideline is "Pedoman Diagnosis dan Tatalaksana Multipel Sklerosis di Indonesia", developed by Indonesian Neurological Association called "Perdossi" in 2015 [12]. The guideline was evaluated using the AGREE II instrument. The scores of each domain summarized in table 1.

Table 1 shows most of the score percentage were more than 50\%. The domain with the lowest score percentage was domain 6 . Table 2 shows a summarized of the guideline treatment recommendations. Guidelines from Indonesia show a specific recommendation for each conditions.

Table 1 Domain scores of multiple sclerosis guidelines

\begin{tabular}{ll}
\hline Domain & Score percentage \\
\hline 1 & 83.33 \\
2 & 88.89 \\
3 & 45.83 \\
4 & 94.44 \\
5 & 54.17 \\
6 & 33.33 \\
\hline
\end{tabular}

This study assessed the quality of MS guidelines in Indonesia using AGREE II instrument with 23 key items organized within 6 domains. Domain 1 is "scope and purposes", is concerned with the overall aim of the guideline, the specific 
health questions, and the target population (items 1-3). Domain 2 is "stakeholder involvement", focuses on the extent to which the guideline was developed by the appropriate stakeholders and represents the views of its intended users (items 4-6). Domain 3 is "rigour of development", relates to the process used to gather and synthesize the evidence, the methods to formulate the recommendations, and to update those (items 7-14). Domain 4 is "clarity of presentation", deals with the language, structure, and format of the guideline (items 15-17). Domain 5 is "applicability", pertains to the likely barriers and facilitators to implementation, strategies to improve uptake, and resource implications of applying the guideline (items 18-21). Domain 6 is "editorial independence", is concerned with the formulation of recommendations not being unduly biased with competing interests (items 22-23) [13].

Our assessment showed that overall quality of the guideline based on AGREE II instrument was strongly recommended for use in practice. Most of the score percentage were more than 50\%. Domain 4 obtained the highest score percentage (94.44\%). It's means the guideline had a spesific recommendations and easily identifiable in an algorithms, table, or summary box. The guideline not only presented the treatment, but also the clinical symptoms, how to diagnose, examinations, and differential diagnoses. The drugs recommendation were summarized in table 2 . The guideline describe the qualifying condition and side effects of each recommendation clearly.

Table 2 Summary of multiple sclerosis drugs recommendation

\begin{tabular}{|c|c|c|}
\hline Condition & $\begin{array}{l}\text { Recommendation } \\
\text { Level }\end{array}$ & $\operatorname{Drug}(\mathbf{s})$ \\
\hline Relaps MS & & $\begin{array}{l}\text { Methylprednisolone IV/oral, 500-1000 mg/day, } \\
\text { 3-5 days }\end{array}$ \\
\hline \multirow{8}{*}{ RRMS } & $1^{\text {st }}$ Line & IFN $\beta$-1b (Betaferon), SC, 250 mg, interval 1 day \\
\hline & & IFN $\beta$-1a (Avonex), IM, 30 mg, once a week \\
\hline & & IFN $\beta-1 \mathrm{a}$ (Rebif), SC, 22 or $44 \mathrm{mg}, 3$ times per week \\
\hline & & $\begin{array}{l}\text { Glatiramer Acetat (Copaxone), SC, } 20 \text { mg, once per } \\
\text { day }\end{array}$ \\
\hline & & Fingolimod (Gilenya), PO, 0.5 mg, once per day \\
\hline & & $\begin{array}{l}\text { Mitoxantrone hydrochloride (Novantrone), IV, } 12 \\
\mathrm{mg} / \mathrm{m}^{2} \text { body surface per } 3 \text { months }\end{array}$ \\
\hline & & Natalizumab (Tysabri), IV, 300 mg, per 4 weeks \\
\hline & $2^{\text {nd }}$ Line & Fingolimod (Gilenya), PO, 0.5 mg, once per day \\
\hline
\end{tabular}

MS: Multiple Sclerosis; RRMS: Relapsing-remitting Multiple Sclerosis; IV: intra venous; SC: sub cutaneous; IM: intra muscular; PO: per oral

Domain 2 and 1 also had a good score percentages ( $88.89 \%$ and 83.33 respectively). The guideline's objectives were to improve the knowledge of MS epidemiology, clinical symptoms, how to diagnose, and the treatment. The target population were MS patients. The target user were neurologist and other specialties who also treat MS patients. All the guideline's development group were included neurologist from various institutions. The guideline used a focus group discussion and literature review methods.

The guideline got a sufficient score percentage in domain $5(54.17 \%)$. The guideline mentioned one of the barriers to its application. MRI is the gold standard to diagnose MS, but eventually most of Indonesian Hospital didn't have a MRI, besides the highly cost. The guideline was applicable and easy to use. The guideline summarized in the box, algorithms, and table.

Domain 3 is important to evaluates the integrity of the guideline development process, but this guideline didn't show a good score percentage (45.83\%). The criteria for selecting the evidence, especially: time periods, search terms used, strengths and limitations, were not well described. Experts prior to its publications did not externally review the guideline. It was said that the guideline would be updated in 5 years, but the procedure for updating the guideline was not clearly described. Domain 6 obatined the lowest score percentage (33.33\%) because lack of the related information. The guidelines had a poor description of funding body and a statement of not biased with competing interests. This guideline had a similar recommendation with another 2 international guideline. 


\section{Conclusion}

There is only one Multiple Sclerosis guideline in Indonesia developed by Indonesian Neurological Association in 2015. Critical appraisal were conducted to measure the quality of the guideline using AGREE II instrument. The result of the critical appraisal showed a good result. The Indonesian MS guideline was strongly recommended for use in practice.

\section{Compliance with ethical standards}

\section{Disclosure of conflict of interest}

The authors declare no conflict of interest.

\section{References}

[1] Mohamed K and Koriem M. (2016). Multiple sclerosis: new insights and trends. Asian Pacific Journal of Tropical Biomedicine, 6(5), 429-440.

[2] Oreja-Guevara C, Wiendl H, Kieseier BC and Airas L. (2014). Specific aspects of modern life for people with multiple sclerosis: Considerations for the practitioner. Therapeutic Advances in Neurological Disorders, 7(2), 137-149.

[3] Giampaolo DL, Bhigjee A, Retief C, Isaacs M, Britz M, Opperman D, Govender R and van Rensburg M. (2013). Guideline for the diagnosis and management of multiple sclerosis: A Southern African perspective. South African Medical Journal, 103(9 Suppl 3), 670-691.

[4] Saguil A, Kane S and Farnell E. (2014). Multiple Sclerosis: A Primary Care Perspective. American Family Physician, 90(9), 644-65.

[5] Minagar A. (2013). Current and Future Therapies for Multiple Sclerosis. Hindawi Publishing Corporation Scientifica.

[6] Lassmann H, Brück W and Lucchinetti CF. (2007). The Immunopathology of Multiple Sclerosis: an Overview. Brain Pathology, 17:210-218.

[7] Goldenberg MM. (2012). Multiple sclerosis review. Pharmacy and Therapeutics, 37(3), 175-184.

[8] Polman CH, Reingold SC, Banwell B, Clanet M, Cohen JA, Filippi M, Fujihara K, Havrdova E, Hutchinson M, Kappos L, Lublin FD, Montalban X, O'Connor P, Sandberg-Wollheim M, Thompson AJ, Waubant E, Weinshenker B and Wolinsky JS. (2011). Diagnostic Criteria for Multiple Sclerosis: 2010 Revisions to the McDonald Criteria. Annals of Neurology, 69, 292-302

[9] Adams AL, Morgan MR and Lindsey WT. (2014). Multiple sclerosis: A review and treatment option updates. Alabama Pharmacy Association. DOI: 334.271.4222

[10] Loma I and Heyman R. (2011). Multiple sclerosis: pathogenesis and treatment. Current Neuropharmacology. 9, 409-416.

[11] Kes VB , Zavoreo I, Šerić V, Solter VV, Cesarik M, Hajnšek S, Pašić MB, Gabelić T, Bašić S, Butković SS, Lušić I, Grbelja LD, Vladić A, Bielen I, Antončić I and Demarin V. (2012). Recommendations for diagnosis and management of multiple sclerosis. Acta Clinica Croatica, 51(1).

[12] Estiasari R, Machfoed MH, Purba J, Imran D, Sugianto P, Sudewi R, Komari N and Sucipto. (2015). Pedoman Diagnosis dan Tatalaksana Multipel Sklerosis di Indonesia. Perdossi: Jakarta.

[13] Brouwers M, Kho ME, Browman GP, Cluzeau F, feder G, Fervers B, Hanna S and Makarski J. (2010). AGREE II: Advancing Guideline Development, Reporting and Evaluation in Healthcare. Canadian Medical Association Journal, 182, E839-42.

\section{How to cite this article}

Pinzon RT and Renita Sanyasi RDL. (2018). Critical appraisal of multiple sclerosis guideline in Indonesia. GSC Biological and Pharmaceutical Sciences, 5(2), 13-16. 